\title{
Preliminary Results on Experimental Modelling of an Adsorption Chiller ${ }^{\star}$
}

\author{
Nayrana Daborer-Prado* (D) and Alois Resch(D) \\ University of Applied Sciences Upper Austria, Energy Research Group ASIC, Austria
}

Received: 28 June 2021 / Received in final form: 30 August 2021 / Accepted: 30 August 2021

\begin{abstract}
Adsorption refrigeration, as a renewable cooling method, has received more attention in the last few years. The interest in this technology comes especially from developing and tropical countries, where the demand for cooling increases every year due to economy and population growth. Based on this scenario, this work aims to develop a numerical model of an adsorption chiller driven with solar energy, which can be used to optimize the cooling system operation of the building where the device is situated and compare it with the current cooling methods in use. The numerical study here presented was created using Matlab/Simulink ${ }^{\mathrm{TM}}$, it is based on a lumped parameter model that relies on physical properties and represents a cooling system using a pair of silica gel-water in a two-bed chiller. In this study, the authors proposed a simplified version of the system and the numerical model, which aims to reduce the simulation time and provide faster results. Besides the temperatures in the system, which range from $52{ }^{\circ} \mathrm{C}$ to $72{ }^{\circ} \mathrm{C}$ in the hot cycle and $12{ }^{\circ} \mathrm{C}$ to $23^{\circ} \mathrm{C}$ in the chilled water cycle, the results also include the variation of water uptake in the two adsorbent beds. In general, the simulated temperature, cooling and heating power and coefficient of performance (COP) are in fair agreement with the literature data, nevertheless, the final results show that improvements still have to be performed.
\end{abstract}

\section{Introduction}

With the rise in social and economic activities all over the world and the consequent increase in greenhouse gases emissions, the importance of renewable energy sources is constantly growing. Special attention is being given to heating and cooling, which accounts for $51 \%$ of the final energy demand in the world, and only $10 \%$ of it is provided by renewable sources [1]. Based on that, several countries have already created policies to encourage the use of less hazardous ways of producing energy, heat and cold [2].

This work focuses on the adsorption refrigeration method, which as a renewable cooling technique, has received more attention in the last few years. This type of technology is needed mostly in developing and tropical countries, where the demand for cooling is more intense. The system investigated here is a silica gel-water adsorption chiller system. Among its main advantages,

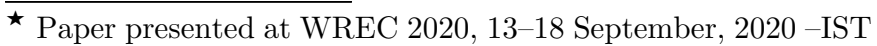
Lisboa.

* e-mail: nayrana.daborer-prado@fh-wels.at
}

the following can be highlighted: (a) can use waste heat with temperatures below $100^{\circ} \mathrm{C}$, which enables the utilization of low temperature heat sources; (b) uses environmental friendly sorption material; (c) small number of moving parts, what decreases the need for maintenance; (d) long life expectancy [3].

The study here presented aims to develop a numerical model of an adsorption chiller driven with solar energy, which can be used to optimize the cooling system operation of the building where the device is situated and compare it with the current cooling methods in use. A similar work was performed in [4-6] were the authors developed different numerical methods to simulate the performance of an adsorption chiller. The novelty in this work was the implementation of a simplified version of the system and numerical model, which was proposed in order to reduce the simulation time required to perform the calculations and allow quick results.

In the next sections a more detailed explanation of the methodology used in this work, as well as the characteristics of the mathematical model developed here will be given. Later on, the experiments performed in the laboratory will be described, as well as its comparison with the simulation results. The last section will present the discussion and conclusions of this work. 


\section{Methodology}

In this work, the first step was to create a mathematical model that could describe the adsorption cooling operation. This process was done using the software Matlab/ Simulink ${ }^{\mathrm{TM}}$, where a lumped parameter model that relies on physical properties was developed based on methods found in the literature [2,7-9]. The next step was to use an adsorption chiller machine installed in the solar thermal laboratory of the University of Applied Sciences Upper Austria, to perform experiments using different input parameters. Subsequently, the findings obtained in the experiments were compared with the results of the mathematical simulation. In order to provide a clear understand of how the process targeted in this paper works, the next section is dedicated to explain the working principle of an adsorption chiller.

\subsection{Working principle of an adsorption chiller}

An adsorption chiller uses a solid material as sorbent instead of a liquid solution. Usually the machine presents four heat exchangers, namely, two adsorption chambers, a condenser and an evaporator [7], which can be seen in Figure 1. In each cycle one of the chambers will be the adsorber while the other will be the desorber, as soon as the sorption material in the adsorption compartment is saturated with water vapor to a certain degree, the chambers switch over their function, so that a continuous cooling effect is produced in the evaporator. In Figure 1, the Adsorption Chamber 1 works as an adsorber and is connected to the evaporator, where a low-pressure refrigerant (water) is evaporated by the use of an external cooling load (chilled water) producing the useful "cold". The solid adsorbent material (silica-gel) filled in the chamber 1 will then adsorb the refrigerant. At the same time, cooling water is used to cool the adsorber and maintain the adsorption process. Regarding the Adsorption Chamber 2, it works as a desorber and is connected to the condenser, which condenses the refrigerant coming out of the Chamber 2 and this condensate returns to the evaporator. The Chamber 2 is heated by the hot water to maintain the desorption of the refrigerant.

\section{Mathematical model}

As previously mentioned, in this work, a simplified version of the mathematical model was proposed and in order to construct it, some assumptions have to be considered, which make the model clearer to understand and simulate:

- All beds are well insulated (no external heat loss to environment).

- The liquid water (condensate) can flow in the evaporator easily.

- The pressure, temperature and the amount of water vapor adsorbed are uniform throughout the beds adsorption.

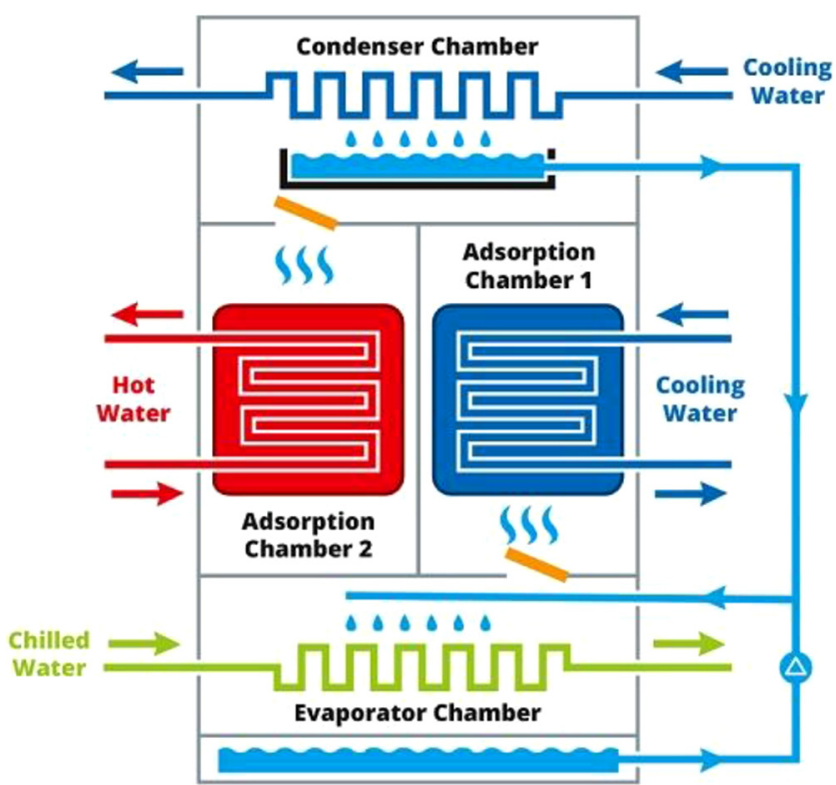

Fig. 1. Working principle of an adsorption chiller. Source [10].

- The condensate will evaporate instantaneously in the evaporator and will be adsorbed in the adsorber immediately.

- The condensate will flow into the evaporator directly and all desorbed water vapor from the desorber will flow into the condenser immediately.

- The thermal resistance between the adsorbent bed and the metal tube is neglected.

- The properties of the metal tube, the fluid and adsorbate vapor (water vapor) are constant.

- Flow resistance arising from the water flowing in the pipeline is neglected.

- The adsorbate gas is assumed to be an ideal gas and the adsorbed phase is considered a liquid.

Based on these assumptions, the energy balance equations of the condenser, adsorber, desorber and evaporator were derived, as well as, a rate of adsorption/desorption and the mass balance in the evaporator.

Rate of adsorption/desorption: The rate of adsorption or desorption is calculated by the use of a linear driving force (LDF) kinetic equation (Eq. (1)) and its coefficients were determined by [11] for a silica gel-water pair. Equation (2) describes the effective diffusivity while the equation (3) defines the equilibrium uptake for the silica gel-water pair.

$$
\begin{gathered}
\frac{\partial w}{\partial t}=F_{0} \frac{D_{S}}{R_{P}^{2}}\left(w^{*}-w\right) \\
D_{S}=D_{S 0} * e^{-E a / R T} \\
w^{*}=0.346\left(\frac{P_{s}\left(T_{r}\right)}{P_{s}\left(T_{a}\right)}\right)^{1 / 1.6}
\end{gathered}
$$




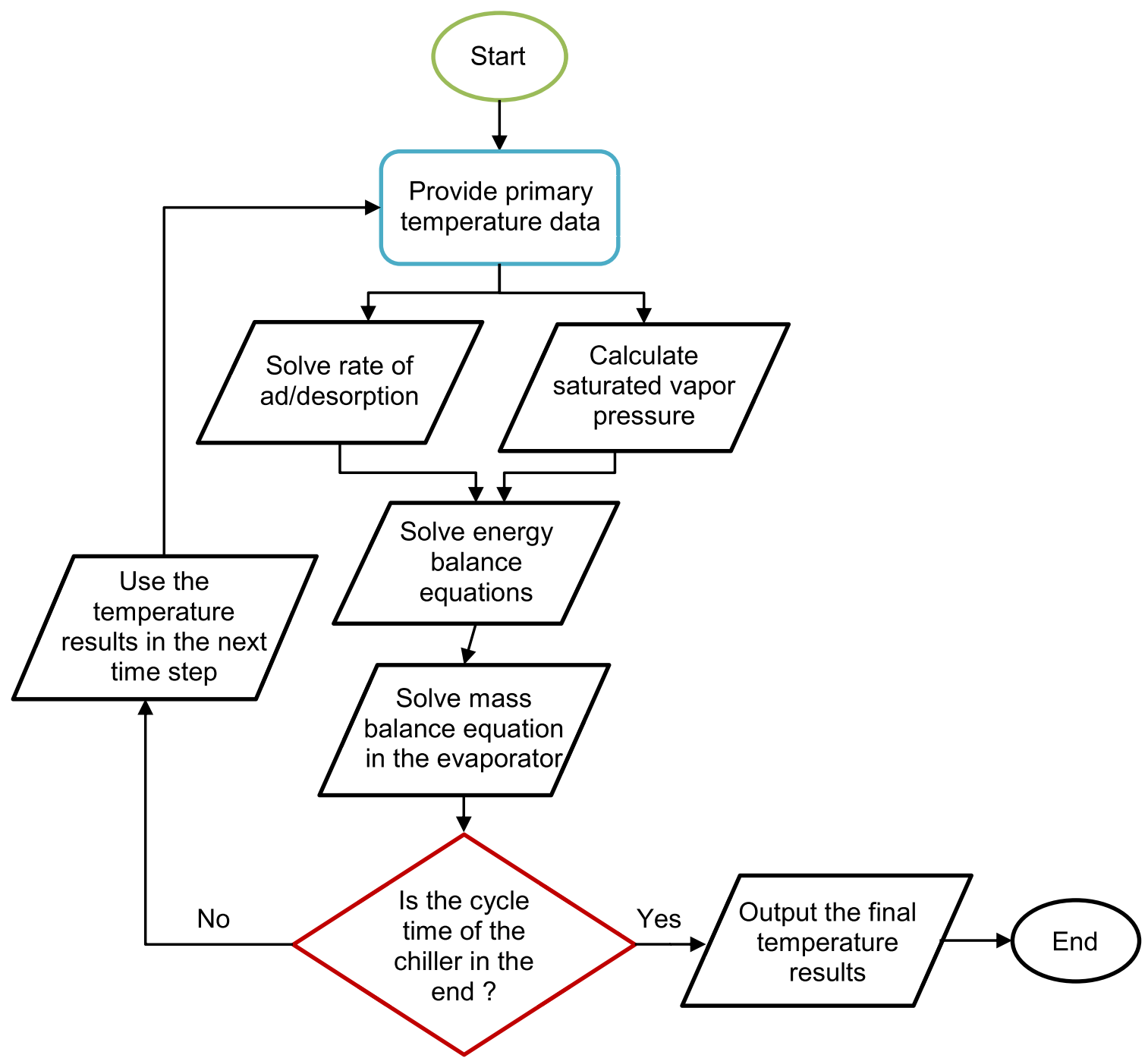

Fig. 2. Flowchart of the model process.

$$
P_{s}(T)=133,32 \exp \left(18,3-\frac{3820}{T-46,1}\right)
$$

where $P_{s}\left(T_{r}\right)$ and $P_{s}\left(T_{a}\right)$ are the saturated vapor pressure of the refrigerant at temperatures $\left(T_{r}\right)$ (water vapor) and $\left(T_{a}\right)$ (silica gel). The saturated vapor pressure $\left(P_{s}\right)$ can be evaluated using the equation (4).

Energy balance of adsorber: is described by the following equation

$$
\begin{aligned}
& \left(m_{a d} c_{a d}+m_{a} c_{a}+m_{a} w c p_{r}\right) \frac{d T_{a d}}{\mathrm{~d} t} \\
& \quad=m_{a} \Delta H_{a d s} \frac{d w}{\mathrm{~d} t}+m_{a} c p_{r, v} \frac{d w}{\mathrm{~d} t}\left(T_{e v}-T_{a d}\right) \\
& \quad+m_{f, a d} c p_{f}\left(T_{f, \text { in }}-T_{f, \text { out }}\right)
\end{aligned}
$$

Energy balance of desorber

$$
\begin{aligned}
& \left(m_{d e} c_{d e}+m_{a} c_{a}+m_{a} w c p_{r}\right) \frac{d T_{d e}}{\mathrm{~d} t} \\
& =m_{a} \Delta H_{a d s} \frac{d w}{\mathrm{~d} t}+m_{f, d e} c p_{f}\left(T_{f, \text { in }}-T_{f, \text { out }}\right)
\end{aligned}
$$

Energy balance of the condenser

$$
\begin{aligned}
\left(m_{r, c d} c p_{r}+m_{c d} c_{c d}\right) \frac{d T_{c d}}{\mathrm{~d} t} & =-m_{a} \frac{d w_{d e s}}{\mathrm{~d} t} L_{v} \\
& -m_{a} c_{p, r} \frac{d w_{d e s}}{\mathrm{~d} t}\left(T_{d e}-T_{c d}\right) \\
& +m_{f, c d} c p_{f}\left(T_{f, \text { in }}-T_{f, \text { out }}\right)
\end{aligned}
$$

Energy balance of the evaporator

$$
\begin{aligned}
\left(m_{e v} c p_{e v}+m_{r, e v} c_{p, r}\right) \frac{d T_{e v}}{\mathrm{~d} t} & =-m_{a} \frac{d w_{a d s}}{\mathrm{~d} t} L_{v} \\
& -m_{a} c_{p, r} \frac{d w_{d e s}}{\mathrm{~d} t}\left(T_{c d}-T_{e v}\right) \\
& +m_{f, e v} c p_{f}\left(T_{f, \text { in }}-T_{f, \text { out }}\right)
\end{aligned}
$$

Mass balance in the evaporator

$$
\frac{d m_{r, e v}}{\mathrm{~d} t}=-m_{a}\left(\frac{d w_{a d s}}{\mathrm{~d} t}+\frac{d w_{d e s}}{\mathrm{~d} t}\right) .
$$




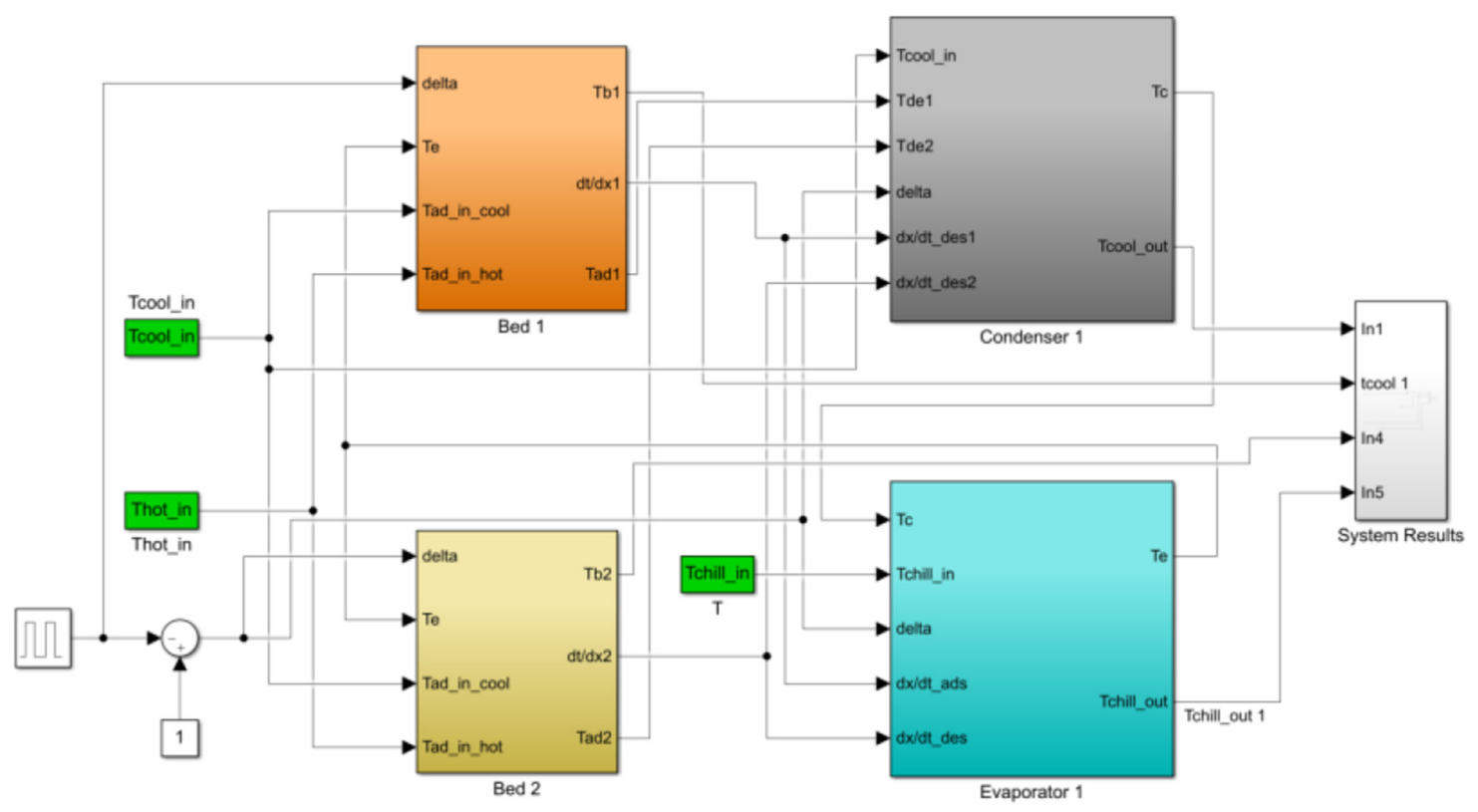

Fig. 3. Simulink view of the system.

All the equations presented above are based on [2], and for more details one can refer to this study. The variables mentioned in all previous equations are described in a nomenclature table in the last section of the paper.

In Figure 2, a flow chart of the mathematical model is represented in order to provide a better understanding on how the process works.

\section{Simulation results}

After the implementation of all equations and proper parameters, some simulations were performed to check the viability of the model. Figure 3 presents the Simulink overview of the model.

The following main parameters were used to execute this simulation:

- Cycle time: four cycles of $420 \mathrm{~s}$ each.

- Hot water inlet temperature: $62{ }^{\circ} \mathrm{C}$.

- Cooled water inlet temperature: $22^{\circ} \mathrm{C}$.

- Chilled water inlet temperature: $15^{\circ} \mathrm{C}$.

- Material mass: $50 \mathrm{~kg}$ of silica gel.

Figure 4 shows the preliminary temperature results obtained with the model. The red and blue full lines represent the temperature inside of each one of the adsorbent beds. As previously mentioned, they interchange functions working as desorber or adsorber alternately, the desorption temperature reaches almost $70^{\circ} \mathrm{C}$ and the adsorption temperature is around $25^{\circ} \mathrm{C}$. The dotted green and light blue lines represent the inlet cooled and chilled water respectively. The full purple line represents the temperature in the evaporator, which is around $10^{\circ} \mathrm{C}$, during adsorption/evaporation the evaporator temperature increases and during the switching phase (precooling/ preheating), it will decrease. The yellow line represents the condenser temperature. In theory, it should decrease during the desorption/evaporation of the refrigerant and

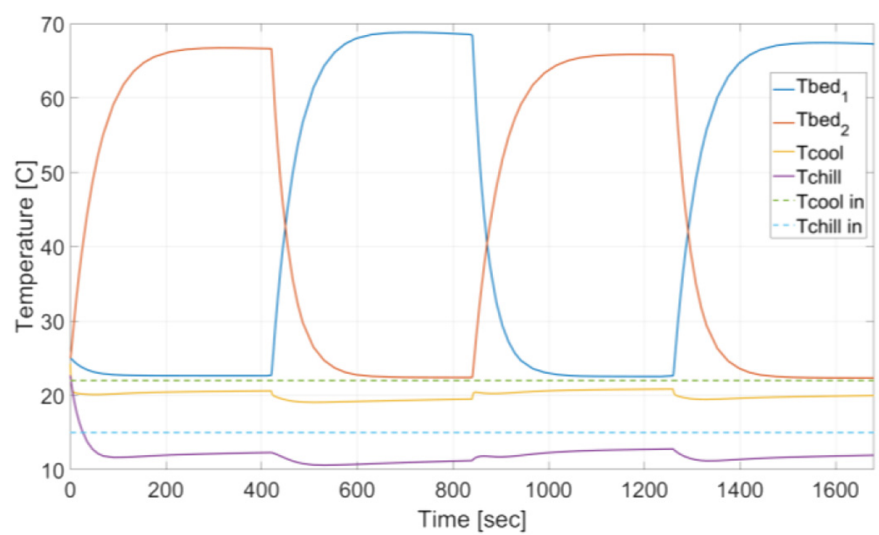

Fig. 4. Overall outlet temperature profile of heat transfer fluid for two beds adsorption chiller.

slightly increase during the switching phase (precooling/ preheating), adversely this behavior is not really represented in the simulation result. Therefore, the model has to be improved in the next phases of the project.

Figure 5 presents the water uptake of the silica gel during the simulation time in each one of the beds. Unfortunately, these results still do not represent what happens in a real experiment. In reality, instead of continuously increasing, during the desorption phase, the water uptake should decrease and during adsorption should again increase. For this reason, further improvements in this model have to be performed and the future developments will be presented in future work.

\section{Experimental results}

In order to validate the mathematical model previously explained, experiments with an adsorption chiller were conducted in the laboratory. The equipment used to 


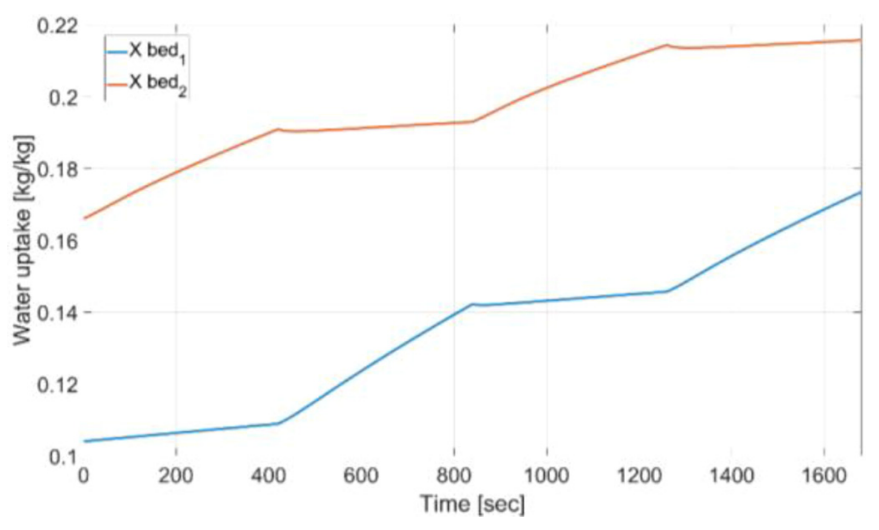

Fig. 5. Variation of water content in each bed.

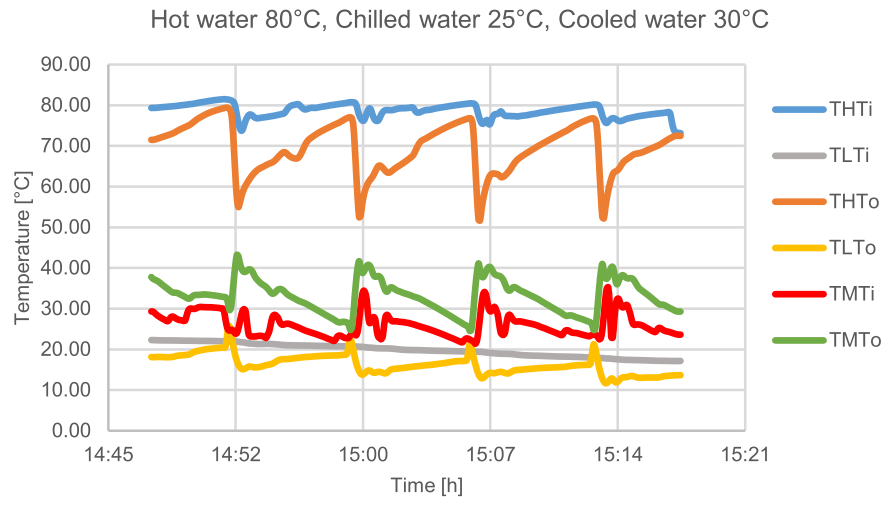

Fig. 6. Temperature variation at $80^{\circ} \mathrm{C} / 25^{\circ} \mathrm{C} / 30^{\circ} \mathrm{C}$.

Table 1. Temperature average and specific heat capacity at $80^{\circ} \mathrm{C} / 25^{\circ} \mathrm{C} / 30^{\circ} \mathrm{C}$.

\begin{tabular}{llllllll}
\hline Temperature $\left[{ }^{\circ} \mathrm{C}\right]$ & Hot water & Chilled water & Cooled water & QHT $[\mathrm{kW}]$ & QLT $[\mathrm{kW}]$ & QMT $[\mathrm{kW}]$ & COP \\
\hline Inlet & 79.5 & 24.52 & 30.89 & & & & \\
Outlet & 71.11 & 20.9 & 37.95 & -24.15 & -12.19 & 41.34 & 0.5 \\
\hline
\end{tabular}

perform the experiments is produced by the company Fahrenheit [12]. The nominal power of the machine is 16.7 $\mathrm{KW}\left(\right.$ at $\mathrm{HT}=85^{\circ} \mathrm{C}, \mathrm{MT}=24^{\circ} \mathrm{C}, \mathrm{LT}=19^{\circ} \mathrm{C}$ ) with a thermal $\mathrm{COP}$ up to 0.65 and a maximum power consumption of $800 \mathrm{~W}$.

The experiments were performed considering different hot, cooled and chilled water input temperatures in order to analyze, which was the best operational point for the machine. Initially, the measurements were performed with the highest hot water storage temperature (maximum $85^{\circ} \mathrm{C}$ ) and successively carried out during the cooling of the hot water storage $\left(\right.$ minimum $\left.55^{\circ} \mathrm{C}\right)$. The chilled water temperature was controlled, depending on the current temperature of the cold-water storage tank, from a maximum of $30^{\circ} \mathrm{C}$ to a minimum of $15^{\circ} \mathrm{C}$ and the cooled water temperature from a maximum of $40^{\circ} \mathrm{C}$ to a minimum of $20^{\circ} \mathrm{C}$. Also, the volume flows used during each of the experiments were the same proposed in the datasheet of the machine.

A hot water tank was used to provide water at the needed temperature to the adsorption chiller, at the same time a cold-water tank supplied the chilled water and the cooled water was provided by the heat exchanger linked to the building's cooling system. The cycle time used during the simulation and the experiments was the same (420s). Nevertheless, the experiment had a duration 2 times longer than the one used during the simulations, for this reason one will notice that 4 cycles of adsorption/desorption are happening, instead of two. Despite the fact that several experiments were carried out in the laboratory, in the next sections, only results of three experiments will be presented and explained.

\subsection{Experiment with hot water at $80^{\circ} \mathrm{C}$, chilled water at $25^{\circ} \mathrm{C}$ and cooled water at $30^{\circ} \mathrm{C}$}

Figure 6 shows the temperature curve at a drive temperature of $80^{\circ} \mathrm{C}$, a chilled water temperature of $25^{\circ} \mathrm{C}$ and a cooling water temperature of $30^{\circ} \mathrm{C}$. The working cycles of the adsorption machine can be clearly seen. The drive temperature (blue) was kept relatively constant at $80^{\circ} \mathrm{C}$ over the measurement period. The output temperature on the chilled side (yellow) could not be controlled, but does not fluctuate much over the individual cycles. The temperature curve simulating the room temperature (gray) is slightly cooled over the measurement period. The cooling water temperature (red, green) could not be kept constant over the entire course of the measurement, as the control was very complex, and fluctuated accordingly over the course of the measurement. It should be noted that this mode of operation was only measured for about 20 minutes and the cycles of the adsorption chiller can be properly recognized.

In Table 1, the inlet and outlet temperatures for this experiment are represented. Based on those values it was possible to calculate the power produced by each cycle and the coefficient of performance (COP) of the system. The hot water is abbreviated as $\mathrm{HT}$, the chilled water as LT (low temperature) and the cooled water as MT (middle temperature). This configuration of temperatures presented the best COP performance when compared to the other experiments performed.

\subsection{Experiment with hot water at $75^{\circ} \mathrm{C}$, chilled water at $25^{\circ} \mathrm{C}$ and cooled water at $35^{\circ} \mathrm{C}$}

In Figure 7 one can notice the variation in the temperature during the 4 cycles of the adsorption chiller for a hot water temperature of $75^{\circ} \mathrm{C}$, chilled water at $25^{\circ} \mathrm{C}$ and cooled water at $35^{\circ} \mathrm{C}$. The hot water temperature varies $\pm 2{ }^{\circ} \mathrm{C}$ over each cycle and at the time of cycle changes, the variation can be as high as $5{ }^{\circ} \mathrm{C}$. The output temperature on the cold side (yellow) could not be controlled, but does not show very large fluctuations over the individual cycles. The cooling water temperature (red, green) could not be kept constant over the entire measurement course and fluctuated accordingly, especially during the cycle shifts. 
Hot water $75^{\circ} \mathrm{C}$, Chilled water $25^{\circ} \mathrm{C}$, Cooled water $35^{\circ} \mathrm{C}$

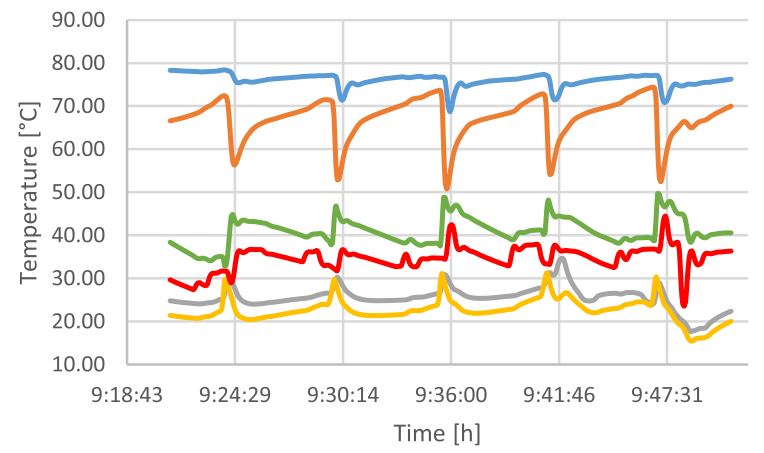

Fig. 7. Temperature variation at $75^{\circ} \mathrm{C} / 25^{\circ} \mathrm{C} / 35^{\circ} \mathrm{C}$.
Hot water $60^{\circ} \mathrm{C}$, Chilled water $15^{\circ} \mathrm{C}$, Cooled water $25^{\circ} \mathrm{C}$

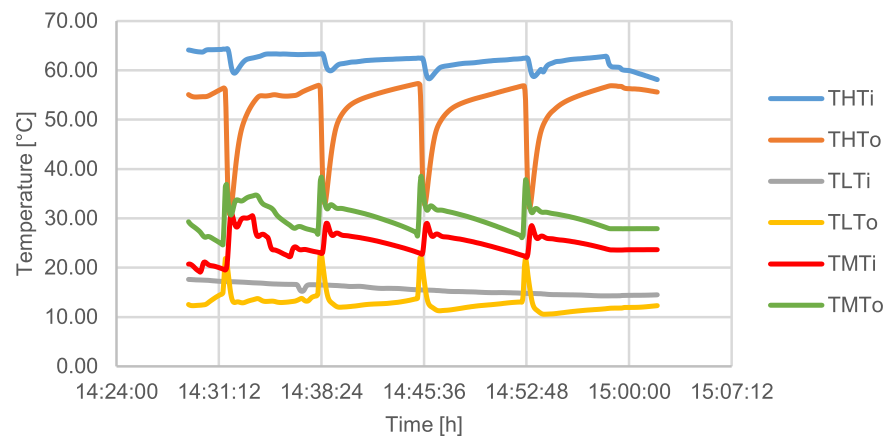

Fig. 8. Temperature variation at $60{ }^{\circ} \mathrm{C} / 15^{\circ} \mathrm{C} / 25^{\circ} \mathrm{C}$.

Table 2. Temperature average and specific heat capacity at $75^{\circ} \mathrm{C} / 25^{\circ} \mathrm{C} / 35^{\circ} \mathrm{C}$.

\begin{tabular}{llllllll}
\hline Temperature $\left[{ }^{\circ} \mathrm{C}\right]$ & Hot water & Chilled water & Cooled water & QHT $[\mathrm{kW}]$ & QLT $[\mathrm{kW}]$ & QMT $[\mathrm{kW}]$ & $\mathrm{COP}$ \\
\hline Inlet & 75.83 & 26.20 & 35.44 & & & & \\
Outlet & 67.35 & 23.32 & 61.55 & -23.76 & -9.74 & 36.77 & 0.41 \\
\hline
\end{tabular}

Table 3. Temperature average and specific heat capacity at $60^{\circ} \mathrm{C} / 15^{\circ} \mathrm{C} / 25^{\circ} \mathrm{C}$.

\begin{tabular}{llllllll}
\hline Temperature $\left[{ }^{\circ} \mathrm{C}\right]$ & Hot water & Chilled water & Cooled water & QHT $[\mathrm{kW}]$ & QLT $[\mathrm{kW}]$ & QMT $[\mathrm{kW}]$ & $\mathrm{COP}$ \\
\hline Inlet & 61.86 & 15.59 & 24.85 & & & & \\
Outlet & 52.63 & 12.88 & 30.10 & -16.63 & -6.09 & 26.11 & 0.366 \\
\hline
\end{tabular}

Table 2 presents the temperature profile of the experiment as well as the power produced by each cycle and the COP. The same abbreviations previously used, are also applied here. With the temperatures used in this experiment the system presented a middle range COP in comparison with the other experiments.

\subsection{Experiment with hot water at $60^{\circ} \mathrm{C}$, chilled water at $15^{\circ} \mathrm{C}$ and cooled water at $25^{\circ} \mathrm{C}$}

Based on Figure 8, it is possible to notice that the hot water temperature (blue) is basically constant during the experiment, and changed up to $10^{\circ} \mathrm{C}$ when the cycles switched. The same happens with the output temperature of the low temperature cycle (yellow), which changed up to $+10^{\circ} \mathrm{C}$ during the switching cycles periods. The temperature curve simulating the room temperature (gray) drops by about $3{ }^{\circ} \mathrm{C}$ over the entire measurement.

As in the previous experiments, the temperatures of the system, for all cycles were calculated and are displayed in Table 3. Based on those values, the power generated by each cycle was computed, as well as the coefficient of performance for the whole system. This experiment presents the lowest $\mathrm{COP}$ in comparison with the others presented here.

\section{Discussion}

Based on the results here presented, the following points should be highlighted. It is important to notice that in all experiments it is possible to identify the exact moment when the cycle change from one bed of silica gel to the other in the adsorption machine, it happens when the hot water outlet temperature (orange) suffers a sharp decrease. In addition, observing Figure 4 and comparing with Figures 6-8, one can note that only the temperature of the hot water leaving the system is represented in the experiment results.

Furthermore, according to the literature, the higher the hot water inlet temperature and the lower the difference between cooled water and chilled water inlet temperatures, the better is the performance of the system. When considering the results here presented, it is possible to observe that the experiment with the input temperatures $80 / 25 / 30$ presented the highest HT inlet temperature, and only $5{ }^{\circ} \mathrm{C}$ difference between LT and MT, therefore it has also the best COP (0.504). When comparing the other two experiments, the difference between LT and MT is the same $\left(10^{\circ} \mathrm{C}\right)$, but the experiment $75 / 25 / 35$ had a better performance and higher COP than the $60 / 15 / 25$ experiment ( 0.41 and 0.366 , respectively) because it presents a higher HT. 
Concerning the use of solar energy as source for the adsorption chiller to cool the building where this arrangement is located, a photovoltaic thermal system (PVT) was used and some advantages and disadvantages were observed. The main advantages are (a) the cooling demand and the solar radiation supply coincide in time; (b) no electrical energy needs to be supplied to the system, it even presents a surplus; (c) the re-cooling energy of the system can be used to preheat other systems, for example, a thermal storage tank, swimming pool heating or ground regeneration. The main disadvantage of the system is its higher complexity, its extensive space requirements and elevated price when compared to conventional models of cooling.

\section{Conclusions}

This study presents a mathematical model and experimental results for a solar adsorption chiller system. The main advantage of this system is that not only its main energy input (solar) but also its working fluid and sorption material (silica gel-water) are environmental friendly. The us of this type of system can substantially decrease the $\mathrm{CO}_{2}$ emission in emerging and tropical countries where the need for cooling is the greatest.

Based on the experiments it is possible to notice that the Coefficient of Performance values ranged between 0.5 and 0.37 , which highlights the fact that the operational points of the machine have a major influence on the overall performance of the system.

When comparing the experiment and the simulation results, despite the small differences between them, the trend of the curves are the same and the performance of the mathematical model fairly agrees with the results from the experiments. Nevertheless, it is also evident that the mathematical model still needs some improvement, which will be performed in the next phases of the project.

Finally, it is important to remark that in order to supply the required input temperatures to the adsorption chiller, the PVT system must present a very large size. Additionally, it can be complicated to find buildings that present the required roof area with an optimal orientation for the installation of an appropriate number for the collectors. Therefore, based on these results, from an economic point of view the use of PVT collectors as heat source for the adsorption chiller is not recommended.

\section{Nomenclature}

$A \quad$ Heat transfer area, $\mathrm{m}^{2}$

COP Coefficient of performance

$\mathrm{Cp} \quad$ Specific heat, $\mathrm{KJ} / \mathrm{kg} \mathrm{K}$

$D_{\mathrm{S} 0} \quad$ Coefficient, $\mathrm{m}^{2} / \mathrm{s}$

E Heat exchanger efficiency

$E_{a} \quad$ Activation energy, $\mathrm{KJ} / \mathrm{kg}$
$L \quad$ Latent heat of vaporization, $\mathrm{KJ} / \mathrm{kg}$

$m \quad$ Mass, $\mathrm{kg}$

$m_{f} \quad$ Mass flow rate, $\mathrm{kg} / \mathrm{s}$

$\Delta H \quad$ Isosteric heat of adsorption, $\mathrm{KJ} / \mathrm{kg}$

$P \quad$ Pressure, $\mathrm{Pa}$

$t \quad$ Time, $\mathrm{s}$

$T \quad$ Temperature, ${ }^{\circ} \mathrm{C}$

$w, w^{*}$ Instantaneous uptake, equilibrium uptake, $\mathrm{kg}$ of refrigerant $/ \mathrm{kg}$ of adsorbent

\section{Subscripts}

$\begin{array}{ll}a & \text { Adsorbent } \\ \text { ad } & \text { Adsorber } \\ \text { ads } & \text { Adsorption } \\ \text { cd } & \text { Condenser } \\ \text { de } & \text { Desorber } \\ \text { ev } & \text { Evaporator } \\ f & \text { Coolant } \\ \text { in } & \text { Inlet } \\ \text { out } & \text { Outlet } \\ r & \text { Refrigerant } \\ r, v & \text { Refrigerant vapor } \\ v & \text { Vapor }\end{array}$

This project is financed by research subsidies granted by the government of Upper Austria. Additional acknowledgement is granted to a group of students of the University of Applied Sciences Upper Austria formed by Manuel Raschhofer, Theresa Laister, Daniel Schnauer, Marcel Urich, Alija Spahic and Christian Wagner, for conducting the experimental measurements presented in this work.

\section{References}

1. REN21, Renewables 2019 Global Status Report, REN21 Secretariat, Paris, 2019

2. G. Najeh, M. Souad, G. Slimane, E.G. Mohammed, B. Riad, Numerical investigation of silica gel-water solar adsorption cooling system with simulink, Am. J. Appl. Sci. 14, 786-794 (2017)

3. S. Akhtar, T.S. Khan, S. Ilyas, M.S. Alshehhi, Feasibility and basic design of solar integrated absorption refrigeration for an industry, Energy Proc. 75, 508-513 (2015)

4. H. Chua, K. Ng, A. Malek, T. Kashiwagi, A. Akisawa, B.B. Saha, Modeling the performance of two-bed, sillica gel-water adsorption chillers, Int. J. Refrigerat. 22, 194-204 (1998)

5. G. Zhang, D. Wang, J. Zhang, Y. Han, W. Sun, Simulation of operating characteristics of the silica gel-water adsorption chiller powered by solar energy, Solar Energy 85, 1469-1478 (2011)

6. M. Schicktanz, T. Nunez, Modelling of an adsorption chiller for dynamic system simulation, Int. J. Refrigerat. 32, 588-595 (2009)

7. R. Sah, B. Choudhury, R. Das, A. Sur, An overview of modelling techniques employed for performance simulation of low-grade heat operated adsorption cooling 
systems, Renew. Sustainable Energy Rev. 74, 364-376 (2017)

8. Q. Pan, R. Wang, Study on operation strategy of a silica gelwater adsorption chiller in solar cooling application, Solar Energy 172, 24-31 (2018)

9. X. Wang, H. Chua, Two bed silica gel-water adsoprtion chillers: an effectual lumped parameter model, Int. J. Refrigerat. 30, 1417-1426 (2007)
10. M. Macnamara, HVAC Online, 19 April 2018. [Online]. Available: https://www.refrigerationandaircon.co.za/index. $\mathrm{php} /$ features/air-conditioning/329-more-efficient-materialdeveloped-for-adsorption-chillers [Accessed 1703 2021]

11. K. Chiharac, M. Suzuki, Air drying by pressure swing adsorption, J. Chem. Eng. Jpn. 16, 293-298 (1983)

12. Technische Daten \& Montageanleitung (TDI) für eCoo 10. Performance. Fahrenheit GmbH, 19. März 2019

Cite this article as: Nayrana Daborer-Prado, Alois Resch, Preliminary Results on Experimental Modelling of an Adsorption Chiller, Renew. Energy Environ. Sustain. 6, 29 (2021) 